\title{
Let's appreciate excellent research in gerontology and geriatrics!
}

\author{
Clemens Tesch-Römer ${ }^{1,2}$ (iD)
}

Received: 25 June 2018 / Accepted: 6 July 2018 / Published online: 12 July 2018

(c) European Geriatric Medicine Society 2018

Scientists working in the fields of aging, from biogerontology over social and behavioral gerontology to geriatric medicine, are awarded by the results of their research. Getting insight into the mechanisms of aging, understanding trajectories across the life course, and bringing forward knowledge about the best interventions in clinical fields and long-term care are highly satisfying for researchers in this field. When working in practical and applied settings, gerontologists and geriatricians will get also positive feedback from patients and clients.

Could we as organized scientists in this field do better? The answer is: "yes, we can"! One way of public recognition are scientific awards granted to excellent scientists at the meetings of our scientific associations. For this reason, the International Association of Gerontology and Geriatrics, European Region (IAGG-ER) has decided to highlight two groups of excellent scientists to the public: experienced scholars who have brought research in gerontology and geriatrics in Europe to new levels, and emergent scholars who are still new in the field, but have nevertheless contributed substantially already.

\section{IAGG-ER award for advances in gerontology and geriatrics}

The "Award of IAGG-ER for Advances in Gerontology and Geriatrics" is given to scientists who have elevated the significance of research in gerontology and geriatrics and who have attained public approval in Europe. Scientists from the three fields of IAGG-ER-biological, clinical, and social-behavioral aging research-are eligible. The award

Clemens Tesch-Römer

ctr@dza.de

1 International Association of Gerontology and Geriatrics, European Region, German Centre of Gerontology, Berlin, Germany

2 Freie Universität Berlin, Berlin, Germany represents an honorable silver medal depicting the emblem of the IAGG European Region and a diploma. Criteria for the award are achievements in gerontology and geriatrics, recognition in Europe as well as substantial publications.

\section{IAGG-ER award for emergent scholars in aging research}

The "European Award for Emergent Scholars in Ageing Research" is given to excellent emergent scholars in European aging research. Criteria for the award are substantial advances to the field of aging research. The candidates should have obtained their Ph.D. within the last 10 years. Links to Europe are important, too: the candidate should have completed their Ph.D. in Europe or they should be currently working in Europe (or both criteria apply).

I would like to invite the readers of the Journal "European Geriatric Medicine" to think about candidates for both awards and nominate them: Let's appreciate excellent research in gerontology and geriatrics! Deadline for nominations is November 30, 2018. More information for both awards can be found at IAGG-ER's website (http://www. iagg-er.net). Both awards will be presented at the next European Congress of IAGG-ER which takes place between May 23 and 25, 2019 in Gothenburg, Sweden (http://www.iagge r2019.se). See you next year in Gothenburg!

\section{Compliance with ethical standards}

Conflict of interest No conflict of interest exists for this manuscript.

Ethical approval This article does not contain any studies with human participants or animals performed by any of the authors.

Informed consent For this type of study formal consent is not required. 